\section{JURNAL ABDIMAS

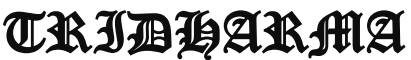 \\ AtA}

P-ISSN 2615-6849, E-ISSN 2622-3686

Jurnal ABDIMAS Vol. 1,No. 3,September 2020,Hal (48-55)

@ Prodi Manajemen Fakultas Ekonomi Universitas Pamulang

Email: abdimasjurnal.unpam@gmail.com Telp: (021) 741-2566

\title{
MOTIVASI MEMBANGUN ENTERPRENEUER BAGI KARYAWAN PT. PERSADA INDONESIA
}

Styo Budi Utomo, Suharni Rahayu, Fauziah Septiani, Nani Mulyani, Jamaludin

Dosen Ekonomi Fakultas Ekonomi Universitas Pamulang

Email : dosen01759@unpam.ac.id, dosen00964@unpam.ac.id, dosen01981@unpam.ac.id , dosen01981@unpam.ac.id,jamaluddinse27@gmail.com

\begin{abstract}
ABSTRAK
Pengabdian ini berjudul Motivasi Membangun Enterpreneuer Bagi Karyawan PT. Persada Indonesia.

Tujuan pengabdian ini adalah untuk menumbuhkan dan meningkatkan rasa untuk mengenbangkan diri berwirausaha, membuka paradigma karyawan dan staf terkait dengan profesionalisme kinerja dan memberikan semangat dan motivasi bagi karyawan dan staf dalam meniti karir di kemudian hari . Metode pelaksanaan pengabdian ini dilakukan dengan kegiatan yaitu melakukan kunjungan ke perusahaan untuk sosialisasi mengenai kegiatan yang akan dilakukan saat kegiatan npengadian kepada masyarakat dilanjutkan dengan penyusunan kegiatan dan materi yang akan disampaikan. Tim pelaksana kegiatan pengabdian pada masyarakat adalah dosen Fakultas Ekonomi jurusan manajemen sebanyak 11 orang. Tim pengabdian memberikan materi tentang Motivasi Membangun Entrerpreneuer Bagi Karyawan PT. Persada Indonesia.

Kesimpulan dari pengabdian ini adalah peserta perlu motivasi untuk menjadi enterpreneuer karena sudah terbiasa menjadi karyawan . Harapan kami dengan pengabdian ini dapat membuka wawasan masyarakat yang diperoleh adalah meningkatnya motivasi bagi karyawan untuk menjadai enterpreneuer selain mereka menjadi karyawan. Denagn bertambhanya wawasan bagi karyawan mengenai bagaimana membangun motivasi unruk dapat menajdi seorang enterpreneuer.
\end{abstract}

\section{Kata Kunci: Motivasi, Enterpereneuer}

\begin{abstract}
ABSTRAC
This dedication is entitled Motivation to Build Entrepreneurs For Employees of PT. Persada Indonesia.

The purpose of this service is to foster and enhance a sense of developing self-employment, opening the paradigm of employees and staff related to professionalism in performance and providing enthusiasm and motivation for employees and staff in pursuing a career in the future. The method of carrying out this service is carried out with activities, namely visiting the company to socialize the activities to be carried out when the community service activity is continued with the preparation of activities and material to be delivered. The implementing team of community service activities are 11 lecturers at the Faculty of Economics majoring in management. The dedication team provided material on Motivation to Build Entrerpreneuers for PT. Persada Indonesia.
\end{abstract}




\section{JURNAL ABDIMAS

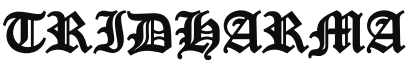

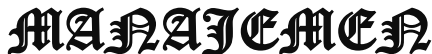

P-ISSN 2615-6849, E-ISSN 2622-3686

Jurnal ABDIMAS Vol. 1,No. 3,September 2020,Hal (48-55)

@ Prodi Manajemen Fakultas Ekonomi Universitas Pamulang

Email: abdimasjurnal.unpam@gmail.com Telp: (021) 741-2566

The conclusion from this dedication is that participants need motivation to become entrepreneurs because they are used to being employees. Our hope with this dedication can open the people's insights gained is increased motivation for employees to become entrepreneurs in addition to being employees. With the addition of insight for employees about how to build motivation to be able to become an entrepreneur.

\section{Keywords: Motivation, Enterpereneuer}

\section{PENDAHULUAN}

Karyawan adalah sumber daya manudia yang merupakan modal dalam suatu usaha, bisnis maupun perusahaan. Seadangkan sumber daya manusia merupakan aset utama dalam sebuah organisasi maupun perusahaan. Sumebr daya manusia sering disebut karyawan atau staf ataupun pegawai.Keberadaan sumber daya manusia memegang peranan yang sangat penting. Tenaga kerja yang memiliki potensi besar untuk menjalankan aktifitas organisasi. Potensi setiap sumber daya manusia yang ada dalam organisasi harus dapat dimanfaatkan sebaik-baiknya. Sehingga mampu memberikan hasil yang maksimal. Organisasi dan karyawan merupakan dua hal yang saling membutuhkan. Jika karyawan mampu membawa keberhasilan organisasi maka kuntungan yang diperoleh akan dipetik oleh kedua belah pihak. Bagi karyawan keberhasilan merupakan aktualisasi potensi diri sekaligus peluang untuk memenuhi kebutuhan hidupnya.. Sedangkan bagi perusahaan atau organisasai keberhasilan merupakan sarana bagi perkembangan dan pertumbuhan perusahaan atau organisasi. Sumber adaya manusia merupakan satu-satunya yang memiliki akal perasaan, keinginan, pengetahuan, dorongan, daya dan karya bagi seorang karyawan merupakan investasi utama yang bernilai dan harus diakui akan keberdaannya sebagai kunci utama bahkan menjadi faktor penentu atas keberhasilan suatu perusahaan atau organisasi dalam menjalankan visi, dan tujuan perusahaan atau organisasi. Itulah sebabnya mengapa peran penting manusia sangat besar pengaruhnya sebagai motor penggerak dan agen perubahan.

Pengertian karyawan : (1) menurut Hasibun karyawan merupakan orang yang menjual jasa, pikiran dan tenaga dan mendapat kompensasi yan besar sudah ditetapkan terlebih dahulu. (2) Menurut Shubri, bahwa karyawan merupakan penduduk yang berusia 1565 tahun atau jumlah seluruh penduduk dalam suatu negara yang memproduksi barang ataupun jasa jukanada permintaan terhadap tenaga kerja mereka dan juka mereka mau beraktivitas pada kegiatan tersebut.

Ciri-ciri karyawan yang baik adalah (1) Jujur, bekerja dimanapun dan menempati posisi apapun sikap yang paling utama adalah jujur.Karena orang yang jujur akan disukai banyak orang dan selalu mendapatkan kepercayaan yang lebih terhadapnya. (2) Bersikap sopan santun, jika seseorang bersikap sopan santun kepada siapapun merupakan maka akan mendapat pengharagaan dari pimpinan dan hal ini merupaka ciri-ciri dari karyawan yang baik. Karyawan yang baik kana mengikuti peraturan yang diberlakukan di perusahaan.(3) Disiplin, Atasan 


\section{JURNAL ABDIMAS

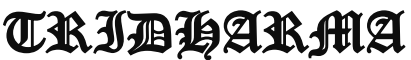

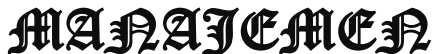

P-ISSN 2615-6849, E-ISSN 2622-3686

Jurnal ABDIMAS Vol. 1,No. 3,September 2020,Hal (48-55)

@Prodi Manajemen Fakultas Ekonomi Universitas Pamulang

Email: abdimasjurnal.unpam@gmail.com Telp: (021) 741-2566 ataupun pimpinan perusahaan sangat suka kepada karyawan yang disiplin dalam mlakukan pekerjaan maupun dalam ketepatan waktu bekerja. (4) Komunikasi yang baik, karywan yang memiliki kekampuan komunikasi yang baik pada umumnya disukai oleh pimpinan.(5) Kerja keras, merupakan ciri-ciri karyaan yang baik dengan kerja keras dan cukup sulit untuk mendapatkan karyawan yang benarbenar mau bekerja keras. (6) Bekerja dengan tim, setiap perusahaan sangat membutuhkan karyawan yang dapat bekerja dengan tim karena permaslahan yang cukup banyak yang dihadapi sebuah perusahaan.

Terdapat dua jenis motivasi yaitu : motivasi intenal dan motibasi eksternal, dimana motivasi internal adalah motivasi yang teradapat dalammdiri individua tau seseorang yang tumbuh dalam diri individua tau seseorang tanpa dipengatruhi oleh orang lain. Sedangkan motivasi eksternal adalah motivasi yang timbul yang diakibatkan oleh dorongan dari luar diri individua atau seseorang maupun yang bersifat rangsangan dari luar diri.

Faktor-faktor

yang mempengaruhi motivasi yaitu ada 2 faktor nya yang pertama adalah factor pemuas. Faktor pemuas biasanya dikenal dengan juga satisfier. Satifier adalah factor yang berasal dari dalam diri individua tau seseorang. Karena hal tesrebut maka stisifier disebut juga sebagai instinc motivation. Adanya factor pemuasa dapat mendorong indidvidu untuk mendapatkan prestasi dan hal tersebut dapat memberikan kepauasan dalam dirinya sendiri.Oleh sebeb itu maka ada bebertapa hal yang dapat memepengaruhi timbulnya factor peamuas yaitu (1) Achievement, achievnebt atau prestasi akan menjadi dorongan utama seseorang untuk bersemangat bekerja yang akan memberikan kualitas bekerja yang baik dan selalu berinovasi menemukan sesuatu yang baru sehingga memebrikan kualitas kerja yang baik.dan memuaskan sehingga dapat mencapai prestasi yang baik. (2)Responsibilty yaitu rasa tanggungjawab. Selain prestasi ada muga responsibility atau tanggungjawab, Setiap individu memiliki rasa tanggungjawab dalam dirinya. Rasa tanggungjawab itulah yang akan mendorong individu untuk melekukan sesuatu pekerjaan lebih baik. (3) Kepuasan Kerja , kepuasan kerja merupakan teori yang dikembangkan dan berasal dari persamaan tingkat kepuasan.. Teori ini mengemukakan bahwa pribadi seseorang akan menentukan kepuasan kerjanya sendiri. Faktor yang kedua yaitu faktor pemelihara, maksdunya adalah faktor pemelihara berasal dari luar individu sehingga dapat disebut sebabagai exctinsic motivastion. Ekstrinsi motivasi dipengaruhi oleh individu lain ataupun hal lain di luar individu tersebut.

Cara meningkaatkan motivasi kerja dimana tidak semua individu atau tidak semua orang memliki motivasi yang tinggi. Maka tidak heran jka pencpaian ataupun prestasi setiap individu berbeda juga. Saat ini fenomena yang terjadi banyak individu yang kehilangan motivasi. Akiabtanya tidak sedikikt yang putus asa bahkan kencendrungannya untuk menyerah. Sehingga membuat individu tersebut tidak semangat menjalankan hidup dan pekerjaannya. Hal tersebut harus membuat individu harus mmpu 


\section{JURNAL ABDIMAS

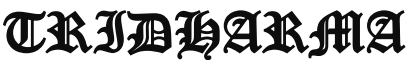

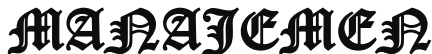

meningkatakan motivasinya.. Namun tidak semua individu mampu meningkatkan motivasi. Dalam diirinya. Beberapa hal yang dapat meningkatkan motivasi adalah (1) Cari pekerjaan sesuai minat dan bakat, hal ini akan dapat meningkatkan motivasi dalam bekerja karena karena pekerjaannyang diadapatkannsesuai dengan minat danbakatnya akan membuat seorang indisvidu bekerja dengan senang hati dan ikhas melakukan pekerejaannya.. Karena senang hati dannikhlas dalam melakukan pekerjaan maka akan banyak inovasi dan ide baru yang dikeluarkan, sehainggapa apapun yang mengacu pada dirinya sendiri untuk selslu berprestasi dalam bekerja. (2) positive Thinking atau berfikiran positif akan sangat berpenagaruh terhadaptinggin rendahnya motivasi yang adaa dalam diri. Dengan berfikir secara positif maka akan mengalir energi -energi positif baik dalam diri. Hal ini akan memebrikan rangasangan yang baik pula, sehingga akan menimbulakn motivasi yang besar di dalam diri untuk melakukan pekerjaann sebaik mungkin. (3) Terus belajar, seorang individu harus belajar dari luar., Dorongan dari luar tersebut dapat mendorong dan meningkatkan motivasi kerja menjadi lebih baik. Dengan terus belajar maka akan mendapatkan makna yanga terdapat di luar. (4) Istirahat Cukup, kualitas istirahat yang cukup juga dapat meningkatkan motivasi di dalam diri. Istirahat dapat menyehatkan badan dan otak maka istirahatlha jika otak dan badan sudah merasa lelah. Kebugaran tubuh yang baikakan dapat meningkatkan motivasi yang baik. (5) Dapatkan Penghargaan yang sesuai, kaeran penghargaan yang sesuai akan dalam sebuah pekerjaan merupakan tujuanndalammhidup. Pengahragaan yang sesuain bisa berupa gaji, kenaikan pangkat, bonus dan sebagainya.

Fungsi dan tujuan motivasi yaitu (1) Menetukan Langkah , dimana motivasi dapat menetukan Langkah dalam hidup, seperti cita-cita yang akan dicapai, prestasi yang akan dicapai dan didapatkan sesuai yang diinginkan ataupunnsegala yang diinginkan. Motivasi ini lah yanag akan menggerakan seseorang untuk melakukan hal-hal dalam hidup. Sehingga motivasininilah yang akan mentukan sukses atau tidak seorang indibidu.(2) Menentukan Keputusan Tidakan, Tidak jarang saat dalam menjalankan kehidupan tentu akan banyak Tindakan-tindakann yang akan diambil mulai dari yang beresiko kkecil hingga beresiko besar. Tujuan dan motivasi itu sendiri adalah untuk menetukan Tindakan yang akan diambil. Tepat atau tidaknya bahkan beresiko kecil atau beresiko besar akan bergantung pada motivasi yang ada dalam diri. Maka harus dikembangkan motivasi yang baik agar segala keputusan yang diambli berdampak baik pada prestasi kerja dan kehidupan. (3) Menyeleksi Perbuatan, melalui motivasi akan dapat menentukan berbagai Tindakan atau perbuatan yang akan diambil ataupunntidak diambil artinya seorang individu dapat akan mampu menentukan perbuatan yang menghasilakan hasil yang baik dan juga dapat memberikan resiko yang kecil.maka perlu mengembangkan motivasi yang lebih baik kkarena akan dapat mengembagkan diri.

\section{RUMUSAN MASALAH}

Dengan mempertimbangkan latar belakang yang telah diutarakan 


\section{JURNAL ABDIMAS

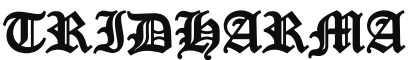

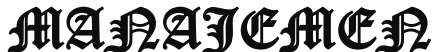

P-ISSN 2615-6849, E-ISSN 2622-3686

Jurnal ABDIMAS Vol. 1,No. 3,September 2020,Hal (48-55)

@ Prodi Manajemen Fakultas Ekonomi Universitas Pamulang

Email: abdimasjurnal.unpam@gmail.com Telp: (021) 741-2566 diatas kami berinisiatif untuk membentuk kegiatan pengabdian masyarakat guna memberi penyuluhan kepada karyawan PT PERONEL ALIH DAYA (PT PERSADA).

Dengan adanya kegiatan penyuluhan tersbut diharapkan karyawan, staff , pegawai mampu menciptakan peluang usaha setelah mereka purna tugas baik sesuai masa pension ataupun terkenda dampak PHK (Pemutusan Hubungan Kerja).

\section{TUJUAN PELAKSANAAN}

1. Menumbuhkan dan meningkatkan rasa untuk mengembagkan diri berwirausaha..

2. Membuka paradigma karyawan dan staf terkait dengan profesionalisme kinerja.

3. Memberikan semangat dan staf dalam meniti karir di kemudian.

\section{TINJAUAN PUSTAKA}

\section{Pengertian Manajemen}

Pengertian manajemen secara umum dapat disimpulkan dari beberapa definisi menurut para ahli. Hal ini karena ada banyak versi definisi manajemen. Misalnya saja manajemen menurut seorang ahli bernama Mary Parker Follet yang mendefinisikan manajemen sebagai seni merampungkan pekerjaan melalui orang lain. Dari definisi tersebut didapati bahwa seseorang yang bertugas sebagai manajer dapat mengarahkan dan mengatur orang lain guna mencapai tujuan organisasi.

Di sisi lain, James A.F Stoner mendefinisikan manajemen sebagai proses pengorganisasian, perencanaan, dan penggunaan SDM supaya mencapai tujuan organisasi yang sudah ditetapkan.
Secara umum, pengertian manajemen merupakan suatu seni dalam ilmu dan pengorganisasian seperti menyusun perencanaan, membangun organisasi dan pengorganisasiannya, pergerakan, serta pengendalian atau pengawasan. Bisa juga diartikan bahwa manajemen merupakan suatu ilmu pengetahuan yang sistematis agar dapat memahami mengapa dan bagaimana manusia saling bekerja sama agar dapat menghasilkan sesuatu yang bermanfaat bagi orang lain maupun golongan tertentu dan masyarakat luas.

Secara etimologis, pengertian manajemen merupakan seni untuk melaksanakan dan mengatur. Manajemen ini juga dilihat sebagai ilmu yang mengajarkan proses mendapatkan tujuan dalam organisasi, sebagai usaha bersama dengan beberapa orang dalam organisasi tersebut. Sehingga, ada orang yang merumuskan dan melaksanakan tindakan manajemen yang disebut dengan manajer.

\section{Fungsi Manajemen}

Pada dasarnya, fungsi manajemen dibagi menjadi tiga, yaitu:

\section{Perencanaan (planning)}

Pernecanaan adalah memikirkan apa yang akan dikerjakan dengan sumber yang dimiliki. Perencanaan dilakukan untuk menentukan tujuan perusahaan secara keseluruhan dan cara terbaik untuk memenuhi tujuan itu. Manajer mengevaluasi berbagai rencana alternatif sebelum mengambil tindakan dan kemudian melihat apakah rencana yang dipilih cocok dan dapat digunakan untuk memenuhi tujuan perusahaan. Perencanaan merupakan proses 


\section{JURNAL ABDIMAS

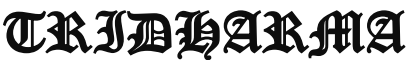

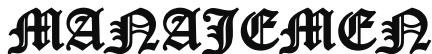

P-ISSN 2615-6849, E-ISSN 2622-3686

Jurnal ABDIMAS Vol. 1,No. 3,September 2020,Hal (48-55)

@Prodi Manajemen Fakultas Ekonomi Universitas Pamulang

Email: abdimasjurnal.unpam@ gmail.com Telp: (021) 741-2566 terpenting dari semua fungsi manajemen karena tanpa perencanaan, fungsi-fungsi lainnya tak dapat berjalan.

\section{Pengorganisasian (organizing)}

Pengorganisasian

mempermudah manajer dalam melakukan pengawasan dan menentukan orang yang dibutuhkan untuk melaksanakan tugas-tugas yang telah dibagi-bagi tersebut. Pengorganisasian dapat dilakukan dengan cara menentukan tugas apa yang harus dikerjakan, siapa yang harus mengerjakannya, bagaimana tugas-tugas tersebut dikelompokkan, siapa yang bertanggung jawab atas tugas tersebut, dan pada tingkatan mana keputusan harus diambil.

3. Pengarahan (directing)

Pengarahan adalah suatu tindakan untuk mengusahakan agar semua anggota kelompok berusaha agar dapat mencapai sasaran sesuai dengan perencanaan manajerial dan usaha.

\section{UNSUR-UNSUR MANAJEMEN}

Setiap perusahaan memiliki unsurunsur untuk membentuk sistem manajerial yang baik. Unsur-unsur inilah yang disebut unsur manajemen. Jika salah satu diantaranya tidak sempurna atau tidak ada, maka akan berimbas dengan berkurangnya upaya untuk mencapai tujuan.

\section{TINJAUAN PUSTAKA}

\section{Pengertian Manajemen Sumber Daya Manusia}

Manajemen adalah ilmu dan seni yang megatur proses pemanfaatan sumber daya manusia dan sumbersumber daya lainya secara efektif dan efesien untuk mencapai suatu tujuan tertentu.
Manajemen sumber daya manusia merupakan bagian dari ilmu manajemen yang memfokuskan perhatianya pada pengaturan peranan sumber daya manusia dalam kegiatan organisasi. Hal ini dikarnakan dalam mencapai tujuanya, organisasi memerlukan sumber daya manusia sebagai pengeelola sistemnya, dan agar sistem ini berjalan, dalam pengelolaanya diperlukan beberapa aspek penting, seprti pelatihan, pengembangan, motivasi dan aspekaspek lainya. Hal ini yang menjadikan manajeman sumber daya manusia sebagai salah satu indikator penting pencapaian tujuan organisasi secara efektif dan efisien.( mila badriah, S.E.,M.M, 15: 2015).

Manusia selalu berperan aktif dan dominan dalam kegiatan organisasi karena manusia menjadi perencana, pelaku, dan penentu terwujudanya tujuan organisasi. Tujuan tidak mungkin terwujud tanpa peran aktif tanpa peran karyawan meskipun alatalat yang dimiliki oleh perusahaan begitu canggih. Alat-alat canggih perusahaan tidak ada manfaatnya bagi perusahaan, jika peran aktif karyawan tidak di ikut sertakan. Mengatur karyawan merupakan hal yang sulit dan kompleks karena mereka mempunyai pikiran, perasaan, status, keinginan, dan latar belakang yang heterogen yang dibawa kedalam suatu organisasi. Karyawan tidak dapat di atur dan dikuasai sepenuhnya seperti mengatur mesin, moda, dan gedung.

Manajemen sumber daya
manusia merupakan bagian dari
manajemen. Oleh karna itu, teori-teori
manajemen umum manjadi dasar
pembahasaannya mengenai pengaturan 


\section{JURNAL ABDIMAS

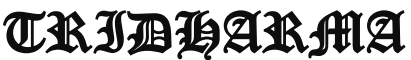

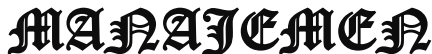

P-ISSN 2615-6849, E-ISSN 2622-3686

Jurnal ABDIMAS Vol. 1,No. 3,September 2020,Hal (48-55)

@ Prodi Manajemen Fakultas Ekonomi Universitas Pamulang

Email: abdimasjurnal.unpam@gmail.com Telp: (021) 741-2566 peranaan manusia dalam menentukan tujuan yang optimal.

Pengaturan itu meliputi masalah perencanaan (human resources planning),

pengorganisasian,pengarahaan,kompen asasi,pengintregrasian, pemeliharaan,ke disiplinan dan pemberhentian tenaga kerja untuk membantu terwujudnya tujuan perusahaan, karyawan, dan masyarakat.

Pengertian manajeman sumber daya manusia menurut malyu S.P. hasibuan ( 2005: 10 ) yang menyatakan bahwa : "manajeman sumber daya manusia adalah ilmu dan seni yang mengatur hubungan dan peranan tenaga kerja yang efektif dan efisien membantu terwujudnya tujuan perusahaan, karyawan, dan masyarakat".

\section{METODE PELAKSANAAN}

Metodepelaksanaan pengabdian ini dilakukan dalam beberapa kegiatan yaitu tahap survei yaitu sosialisasi dilakukan dengan menyusun berbagai hal yang akan disampaikan pada saat kegiatan pengabdian yang akan dilakukan yang meliputi: penyusunan materi yang akan diberikan, penyusunan jadwal pemberian materi, pembagian tugas tim pengabdian dan survei ke lokasi pengabdian. Tahap sosialisasi yaitu sebelum kegiatan pengabdian dilaksanakan terlebih dahulu dilakukan tahap sosialisasi yaitu melakukan silaturahmi dengan ketua yayasan, menyampaikan maksud dan tujuan pengabdian ini. Pada tahap ini juga dilakukan jalinan kerjasama dan menentukan jadwal kegiatan pengabdian. Tim pelaksana kegiatan pengabdian pada masyarakat adalah dosen Fakultas Ekonomi jurusan manajemen sebanyak 5 orang. Tim pengabdian memberikan materi tentang motivasi membangun entrepreneur bagin karyawan PT. Persada Indonesia.

\section{HASIL DAN PEMBAHASAN}

Pengabdian Masyarakat (LPPM) Universitas Pamulang yang dilakukan oleh dosen-dosen program studi Manajemen telah berjalan dengan lancar dan mendapat sambutan hangat dari tempat pelaksanaan kegiatan ini yaituPT.Persada Indonesia, Tangerang Selatan .

Harapan kami dengan pengabdian ini dapat membuka wawasan masyarakat yang diperoleh adalah bertambahnya keilmuan bagi para karyawan untuk meningkatkan motivasi kerja dan untuk menjadi entrepreneur dan memliki pengahsilan tambahan selaian mendapat kan gaji bulana dan dapat meningkatkan taraf hidup karyawan PT. Persada Indonesia

\section{KESIMPULAN DAN SARAN Kesimpulan}

Peserta kurang mengerti apa itu apa dan bagaimana membangun motivasi untuk menjadi seorang enterpreneuer yang dapat memebrikan dampak pada masa depannya dan perbaikan secara income karyawan sehungga tidak hanya berharap penghasilan dari gaji perusahaan.

\section{Saran}

Setelah pengabdian ini diharapkan peserta dapat memiliki motivasi yang lebih kuat dan lebih baik untuk menajdi enterpreneuer sehingga dapat memeliki income lebih setiap bulannya. Dan tidak hanya berharap 


\section{JURNAL ABDIMAS

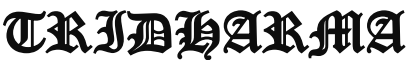

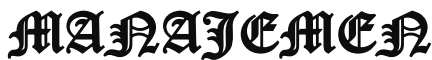

P-ISSN 2615-6849, E-ISSN 2622-3686

Jurnal ABDIMAS Vol. 1,No. 3,September 2020,Hal (48-55)

@ Prodi Manajemen Fakultas Ekonomi Universitas Pamulang

Email: abdimasjurnal.unpam@gmail.com Telp: (021) 741-2566 dari gaji bulanan yang diberikan oleh perusahaan.

\section{DAFTAR PUSTAKA}

Arikunto, Suharsimi. 2008. DasarDasar Evaluasi Pembelajaran. Jakarta: Bumi Aksara. 308 hlmn.

Dewanti, Retno, (2008), Kewirausahaan, Jakarta: Mitra Wacana Media

Malayu Hasibuan, 2010, Organisasi dan Motivasi , dasar Peningkatan Produktivitas. Jakarta: Bumi Aksara

Pasaribu, V. L. D., Susanti, F., \& Hartuti, E. T. K. (2019). Memotivasi Siswa dan Siswi SMK Letris Indonesia di Dalam Menentukan Pilihan Untuk Melanjutkan Pendidikan Atau Bekerja Setelah Lulus Sekolah. Jurnal Pengabdian Dharma Laksana, 1(2), 161-172.

Pasaribu, V. L. D., Agrasadya, A., Shabrina, N., \& Krisnaldy, K. (2020). MENJADI ENTERPRENEUR MUDA YANG MEMILIKI JIWA LEADERSHIP UNTUK MENGHADAPI MASA DEPAN. $A b d i$ Laksana, 1(1).

Pasaribu, V. L. D., Elburdah, R. P., Sudarso, E., \& Fauziah, G. (2020). PENGGUNAAN MANAJEMEN WAKTU TERHADAP PENINGKATAN PRESTASI BELAJAR DI SMP ARAISIYAH. Jurnal ABDIMAS Tri Dharma Manajemen, 1(1).

Pasaribu, V. L. D., Sulaiman, S., Sutiman, S., Thaharudin, T., \& Purnomo, B. Y. (2020). PENGENALAN LETAK POSYANDU TERDEKAT DIKELURAHAN PISANGAN DENGAN MANAJEMEN PEMASARAN REVOLUSI 4.0 UNTUK MENINGKATKAN PENGETAHUAN MASYARAKAT LETAK DAN FUNGSI POSYANDU TERDEKAT PADA KELURAHAN PISANGAN. DEDIKASI PKM, $1(1), 105-110$.

Pasaribu, V. L. D., Oktrima, B., Prabowo, B., Arianto, N., \& Haryoko, U. B. (2020). PROGAM PENDAMPINGAN DAN PENYELENGGARAAN PENDIDIKAN ANAK PADA USIA DINI TERHADAP PRESTASI BELAJAR DILINGKUNGAN RT
020 RW 009. KEL GIRI PENI. KEC WATES. YOGYAKARTA. JURNAL LOKABMAS KREATIF, 1(1), 71-75.

Suryana. (2003),

Kewirausahaan.Jakarta: Salemba

Empat

\section{DOKUMENTASI KEGIATAN}

FOTO
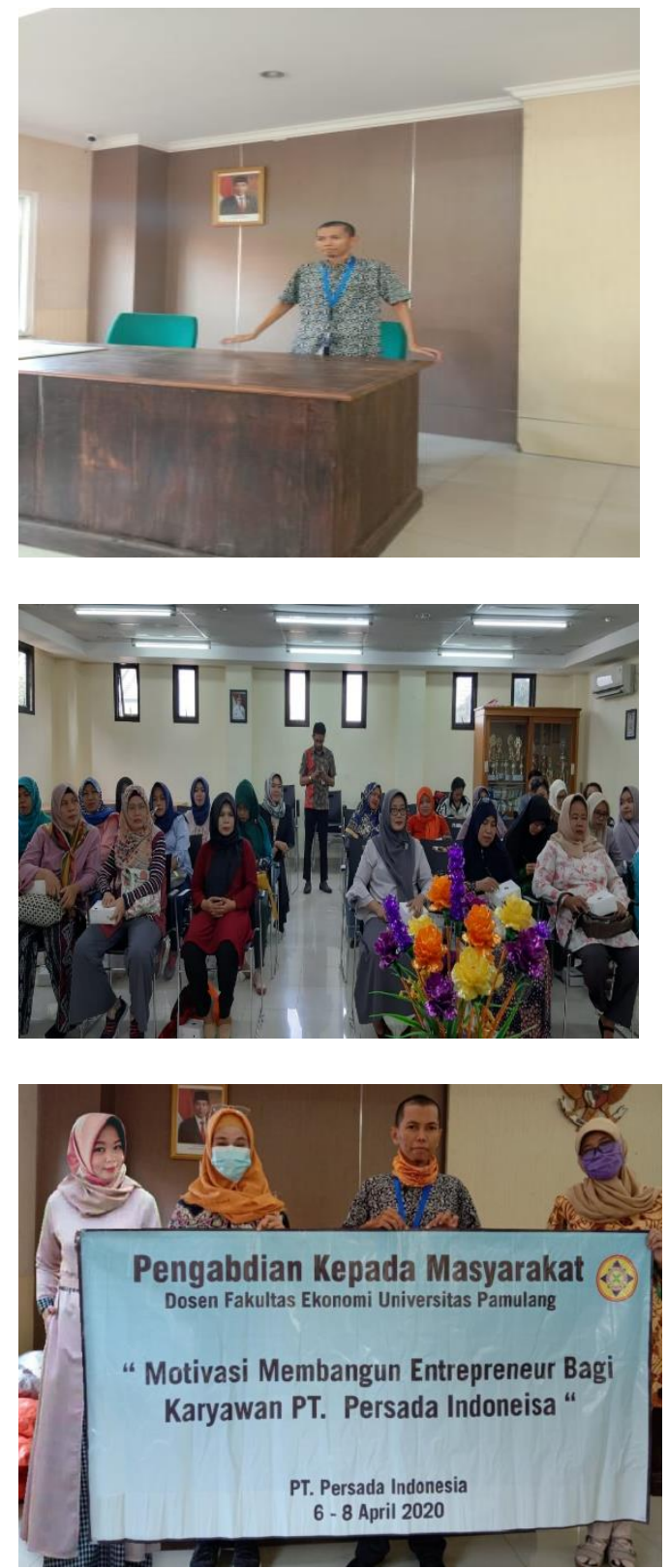